\title{
Evaluation of Kharma scale as a predictor of lower third molar extraction difficulty
}

\author{
Abdurrahman A. Al-Samman \\ B.D.S. M.Sc. Oral and Maxillofacial Surgery. Specialist, Department of the Oral Surgery, Tikrit Specialized Dental Centre / \\ Salahiddin Health Directorate/ Ministry of Health/ IRAQ
}

Correspondence:

Department of the Oral Surgery,

Tikrit Specialized Dental Centre /

Salahiddin Health Directoratel

Ministry of Health/IRAQ

abdalsamman@yahoo.com

Al-Samman AA. Evaluation of Kharma scale as a predictor of lower third molar extraction difficulty. Med Oral Patol Oral Cir Bucal. 2017 Nov 1;22 (6):e796-9.

http://www.medicinaoral.com/medoralfree01/v22i6/medoralv22i6p796.pdf

Received: 04/07/2017 Accepted: 06/09/2017

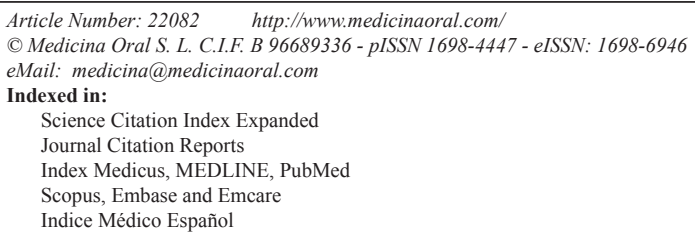

\begin{abstract}
Background: The Evaluation of the degree of lower third molar (L3M) extraction difficulty is extremely important for both clinicians and patients. This study aimed to evaluate the validity of a new index (Kharma scale) as a preoperative predictor index of the difficulty of surgical removal of impacted L3M.

Material and Methods: Extraction difficulty of a series of 49-impacted L3M was predicted preoperatively by Kharma scale, and postoperative difficulty was assessed with a modified Parant scale.

Results: The sensitivity of Kharma scale, as a predictor of difficulty, was $18.2 \%$ and the specificity was $68.4 \%$. Likelihood ratios for the Kharma categories also indicated that the scale is of little value for predicting a difficult extraction. There was no significant association between the Kharma score and duration of operation, but highmodified Parant scores were significantly associated with longer operations.

Conclusions: The proposed Kharma scale was unreliable as preoperative predictor of the L3M extraction difficulty, and both radiological and clinical information must be taken into account.
\end{abstract}

Key words: Kharma scale, prediction scale, lower third molar, extraction difficulty.

\section{Introduction}

Evaluation of the degree of lower third molar (L3M) extraction difficulty is extremely important to design correct treatment strategy and to reduce the risk of complications. Therefore, having optimal scale to predict L3M extraction difficulty continues to challenge clinicians. Several methods have been established for preoperative estimation of difficulty, but they found invalid (1-4) or of limited clinical use $(2,3,5,6)$.

Among these scales, is the Pederson scale, which is widely cited in oral and maxillofacial surgical texts as a useful tool to predict the difficulty of extraction of L3M (1). However, diverse clinicians have questioned its performance $(1,3)$.

Recently, Kharma et al. (7) proposed a new scale; which is a modification of Pederson scale; that took into account the anatomical form of the tooth roots. They claimed that this new estimating index is more reliable and accurate than Pederson scale, and significantly correlated with postoperative difficulty rated by modified Parant scale (7).

The aim of this study was to evaluate Kharma scale's prediction accuracy. 


\section{Material and Methods}

We evaluated the surgical extractions of 49 L3M performed in patients (41male, 8 female, mean (SD) age 27.5(5.7) years) who presented to the Department of the Oral Surgery, The Left Specialized Dental Centre, Mosul, Iraq from November 2015 to October 2016. The ethics committee of the Iraqi Ministry of Health approved the study.

All operations were done by two surgeons who had six and nine years' experience in oral and maxillofacial surgery, and according to standard protocols under local anesthesia.

Preoperatively, the surgeon predicted the difficulty of extraction from panoramic radiographs using Kharma scale. After the operation, difficulty was assessed using the modified Parant scale (MPS) (Table 1). The duration of operation was also recorded by a stopwatch (from start of incision to final suture).

By using descriptive statistics of IBM SPSS Statistics 23, sensitivity, specificity, and likelihood ratios were calculated considering the MPS as a reference. In addition, the correlation between the operative time and the

Table 1. Criteria of Kharma and modified Parant scales.

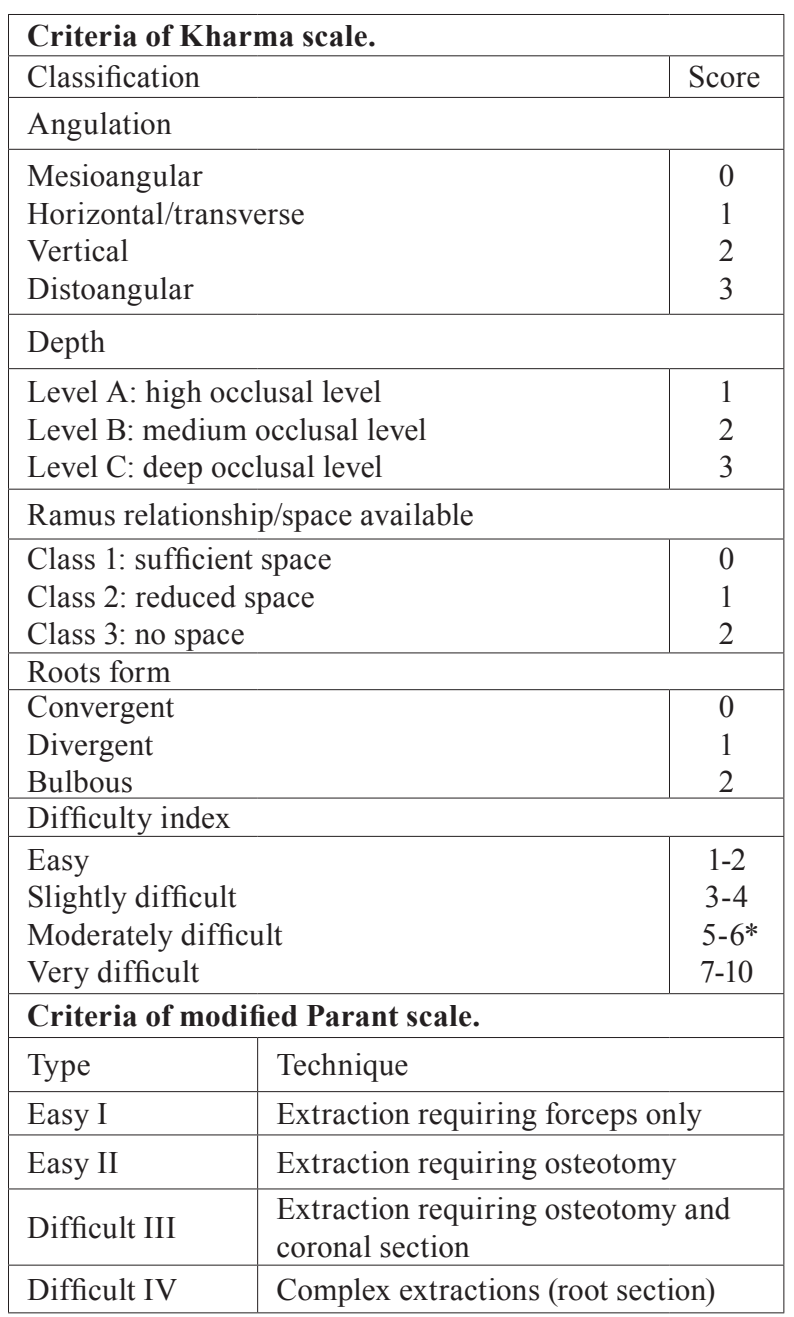

*In the original index, moderately difficult was graded as5-7 difficulty of operation as proposed by both Kharma and modified Parant scales were also assessed by analysis of variance test considering a probability values less than 0.05 as significant.

\section{Results}

Table 2 review the classification of difficulty of 49 extractions by preoperative Kharma scale and postoperative MPS.

The results indicate that 18 extractions are easy I according to MPS. By contrast, only 14 cases are classified as easy by Kharma scale. Kharma scale showed a low sensitivity $(18.2 \%)$ for difficulty prediction of difficulty (11 extractions classified as difficult by the MPS, among them, only 2 cases were classified as moderately difficult by Kharma scale), and limited specificity of $68.4 \%$.

Likelihood ratios for prediction of each class of Kharma scale were not significant as they ranged between 0.5 and 2 (Table 3 ).

The mean time of operative duration of each category of Kharma and modified Parant scale illustrated in table

Table 2. Classification of 49 extractions by preoperative Kharma scale and postoperative modified Parant scale

\begin{tabular}{|c|c|c|c|c|c|c|}
\hline \multirow{2}{*}{} & \multicolumn{5}{|c|}{ Modified Parant scale } & \\
\cline { 2 - 6 } & \multicolumn{2}{|c|}{ Easy } & \multicolumn{2}{c|}{ Difficult } & \\
\cline { 2 - 6 } & I & II & III & IV & \\
\hline Kharma scale & \multicolumn{5}{|l}{} & Total \\
\hline Easy & 4 & 5 & 5 & - & 14 \\
\hline Slightly difficult & 11 & 6 & 4 & - & 21 \\
\hline Moderately difficult & 3 & 8 & 2 & - & 13 \\
\hline Very difficult & - & 1 & - & - & 1 \\
\hline Total & 18 & 20 & 11 & 0 & 49 \\
\hline
\end{tabular}

Table 3. Predictive values (P1, P2) and likelihood ratios of the different Kharma categories for prediction of each modified Parant category.

\begin{tabular}{|c|c|c|c|c|c|}
\hline & \multicolumn{4}{|c|}{ Modified Parant scale } & \multirow[b]{3}{*}{$\begin{array}{l}\text { Like- } \\
\text { lihood } \\
\text { ratios }\end{array}$} \\
\hline & \multicolumn{2}{|c|}{ Difficult } & \multicolumn{2}{|c|}{ Easy } & \\
\hline & No. & $\mathrm{P} 1$ & No. & $\mathrm{P} 2$ & \\
\hline \multicolumn{6}{|l|}{ Kharma scale } \\
\hline Easy & 5 & 0.45 & 9 & 0.24 & 1.88 \\
\hline Slightly difficult & 4 & 0.36 & 17 & 0.45 & 0.8 \\
\hline Moderately difficult & 2 & 0.18 & 11 & 0.29 & 0.62 \\
\hline Very difficult & 0 & 0 & 1 & 0.03 & 0 \\
\hline Total & 11 & & 38 & & \\
\hline
\end{tabular}

Likelihood ratios (LR), calculated as P1/P2. Significant likelihood ratios for prediction must be below 0.5 or above 2 .

P1: Predicted probability of difficulty.

P2: Predicted probability of easiness. 
Table 4. Mean (range) duration of operation (min) in each category of Kharma and modified Parant scale.

\begin{tabular}{|c|c|c|c|c|c|}
\hline \multicolumn{6}{|c|}{ Modified Parant scale } \\
\hline & Easy I & Easy II & Difficult III & Difficult IV & $P$ \\
\hline $\begin{array}{l}\text { Duration } \\
\text { (min) }\end{array}$ & $6.68(21.17)$ & $\begin{array}{l}11.80 \\
(17.0)\end{array}$ & $\begin{array}{c}18.65 \\
(23.62)\end{array}$ & - & .716 \\
\hline \multicolumn{6}{|c|}{ Kharma scale } \\
\hline & Easy & Slightly difficult & Moderately difficult & Very difficult & $P$ \\
\hline $\begin{array}{l}\text { Duration } \\
\text { (min) }\end{array}$ & $11.6(19.18)$ & $\begin{array}{l}10.54 \\
(32.0)\end{array}$ & $\begin{array}{l}12.67 \\
(30.0)\end{array}$ & $\begin{array}{l}15 \\
(0)\end{array}$ & .007 \\
\hline
\end{tabular}

(4) which indicated that operations with longer duration was significantly correlated with higher modified Parant scores $(P=.007)$. By contrast, no significant correlation was exist with Kharma scores $(P=.716)$.

\section{Discussion}

Clinical and radiographical findings should be considered preoperatively for correct evaluation of L3M extraction. It helps in prediction of operative difficulty for correct treatment plant and improves the level of patients' satisfaction with the treatment received $(1,8)$.

Several methods were established for preoperative estimation of difficulty like Pederson scale, which was used by clinicians as a useful tool to predict of L3M extraction difficulty (1). However, The meta-analysis of the current literatures concluded that Pederson scale is not a reliable prediction index in L3M surgery (9).

WHARFE scale (10) was also proposed, but is rarely used in practice duo to their complexity (1). Other variables had been considered in MRACBS scale (6) including L3M relation to inferior alveolar and lingual nerves. It is of limited clinical application due to the need to the cone beam computed tomography in classification.

Santamaria et al. (11) points to the importance root patterns in determining L3M extraction difficulty. Other researchers $(2,3)$ took into account the curvature, width and number of L3M roots in their difficulty prediction index.

Kharma scale proposed a new difficulty prediction index based on 4 factors: tooth angulation, the depth of the third molar in the mandible, the relationship with the ramus/space available, and root form (7). It is similar to Pederson index in that it measures the same parameters in addition to root forms, and close to Yuasa scale (3) as the former assess the same parameters in addition to tooth angulation. However, Kharma scale, in this study, reported $85.7 \%$ false +ve. and $25.7 \%$ false - ve. and showed a very low sensitivity $(18.2 \%)$ and a specificity of $68.4 \%$. In contrast, Yuasa scale in a preliminary study (3) recorded $8.3 \%$ false +ve and 15\% false -ve. which resulted in high sensitivity $(85 \%)$ and specificity (92\%). The false -ve cases causing problems for both the practitioners and patients (3).
In this study, the MPS was considered as a reference standard index of surgical difficulty as it found reliable and consistent with operative difficulty by researchers $(1,7,8,12)$. The results of this study was in agreement with previous studies where the MPS was found significantly correlated with surgical time $(P=0.007)$. However, Kharma scale fail to correlate with $P$ value of 0.716 . The results indicate that the Kharma scale has poor sensitivity when over $85 \%$ of difficult extractions were not identified. In addition, likelihood ratios for prediction of the different difficulties of the Kharma scale from the categories of MPS also indicate that Kharma scale is of little value in predicting operative difficulty (a significant likelihood ratios for prediction must be below 0.5 or above 2) (13). This is may be owing to the lack of consideration of various relevant factors, such as bone density, periodontal space, flexibility of the cheek, and nerve proximity. In addition, curvature of the root is sometimes an unpredictable factor, as it is often not visible in panoramic radiographs (3).

In conclusion, and depending on the current results, the proposed Kharma scale was unreliable as preoperative predictor of the L3M extraction difficulty, and both radiological and clinical information must be taken into account.

\section{References}

1. Diniz-Freitas M, Lago-Mendez L, Gude-Sampedro F, SomozaMartin JM, Gándara-Rey JM, and García-García A. Pederson scale fails to predict how difficult it will be to extract lower third molars. Br J Oral Maxillofac Surg. 2007;45:23-6.

2. Gbotolorun OM, Arotiba GT, Ladeinde AL. Assessment of factors associated with surgical difficulty in impacted mandibular third molar extraction. J Oral Maxillofa Surg. 2007;65:1977-83.

3. Yuasa H, Kawai T, Sugiura M. Classification of surgical difficulty in extracting impacted third molars. Br J Oral Maxillofac Surg. 2002;40:26-31.

4. García-García A, Sampedro FG, Rey JG, Vila PG, Martin MS. Pell-Gregory classification is unreliable as a predictor of difficulty in extracting impacted lower third molars. Br J Oral Maxillofac Surg. 2000;83:585-7.

5. Santosh P. Impacted Mandibular Third Molars: Review of literature and a proposal of a combined clinical and radiological classification. Ann Med Health Sci Res. 2015;5:229-34.

6. Juodzbalys G, Daugela P. Mandibular third molar impaction: Review of literature and a proposal of a classification. J Oral Maxillofac Res 2013;4:e1-12.

7. Kharma MY, Sakka S, Aws G, Tarakji B, Nassani MZ. Reliability 
of Pederson scale in surgical extraction of impacted lower third molars: Proposal of new scale. J Oral Diseases. 2014;2014:1-4.

8. Barreiro-Torres J, Diniz-Freitas M, Lago-Méndez L, GudeSampedro F, Gándara-Rey JM, García-García A. Evaluation of the surgical difficulty in lower third molar extraction. Med Oral Patol Oral Cir Bucal. 2010;15:e869-74.

9. Bali A, Bali D, Sharma A, Verma G. Is Pederson index a true predictive difficulty index for impacted mandibular third molar surgery? A meta-analysis. J. Maxillofac. Oral Surg. 2013;12:359-64.

10. MacGregor AJ. The impacted lower wisdom tooth. Oxford: Oxford University Press; 1985.

11. Santamaria J, Arteagoitia I. Radiologic variables of clinical significance in the extraction of impacted mandibular third molars. Oral Surg Oral Med Oral Pathol Oral Radiol Endod.1997;84:469-73.

12. Janjua OS, Baig Z, Manzoor A, Abbas T. Accuracy of Pederson and modified Parant scale for predicting difficulty level of mandibular third molars. Arch Orofac Sci. 2013;8:9-13.

13. Jaeschke R, Guyatt GH, Sackett DL. Users' guides to the medical literature. III. How to use an article about a diagnostic test. B. What are the results and will they help me in caring for my patients?

JAMA. 1994;271:703-7.

Funding: None.

Conflicts of Interest

The author declare that there is no conflict of interest related to this study. 